\title{
Intra-annual thermal patterns in the main rivers of the Sabie Catchment, Mpumalanga, South Africa
}

\author{
NA Rivers-Moore* and GPW Jewitt \\ School of Bioresources Engineering and Environmental Hydrology, University of KwaZulu-Natal, P/Bag X01, Scottsville 3209, \\ South Africa
}

\begin{abstract}
Water temperatures serve as indices of catchment condition, being a function of a multitude of variables acting as both drivers and buffers, at different temporal and spatial scales. Data loggers were used to record time series of hourly water temperatures within the Sabie, Sand and Marite Rivers of the Sabie catchment, Mpumalanga, South Africa. Two years of hourly water temperatures were scaled up to provide daily statistics of water temperatures, which provided information on intra-annual thermal variability as well as how this changed along the longitudinal axis of the Sabie River. In general, mean and maximum water temperatures, and thermal variability, increased with downstream distance in the Sabie River. Water temperatures in the two main tributaries of the Sabie River, viz. the Marite and Sand Rivers, displayed higher maxima and lower minima than corresponding sites in the Sabie River. Further research on the role of hyporheic water and the contribution of tributaries is proposed, together with additional long-term collection of water temperature time series.
\end{abstract}

Keywords: water temperatures; Sabie River; intra-annual variability

\section{Introduction}

A river's annual thermal regime is one of its most important water quality parameters, being a key component in determining the distribution of aquatic communities (Nikolsky, 1963; Smith 1979; 1981; Ward 1985; Weeks et al., 1996; Sullivan et al., 2000; Caissie et al., 2001; Dunham et al., 2003). Furthermore, most of the chemical, physical and biological properties of water are temperature-dependent (Smith, 1981). The link between abiotic process and biotic pattern is an important river management consideration, if biodiversity is to be maintained within river systems. A fundamental step in this process is characterising and understanding water temperature patterns, particularly as an environmental gradient from the headwaters downstream.

Water temperatures are a function of many variables operating at different spatial and temporal scales, and may serve as an index of catchment condition (Poole and Berman, 2001; Johnson, 2003). Drivers of a river's thermal regime (for example, solar radiation, surface friction and tributary flows) are in dynamic equilibrium with thermal losses through heat transfer processes, such as evaporation (Bartholow, 1989). Thermal gains or losses to a river are in turn "buffered" by factors such as the degree of riparian shading (Gray and Edington, 1969), flow volumes, channel form and the contribution of the hyporheic zone (i.e. the stream or rivers alluvium and associated groundwater from the alluvial aquifer) (Poole and Berman, 2001). Differences in flow volume between headwaters and lower reaches result in the thermal lag (i.e. the time difference between water temperature response to air temperatures) becoming more pronounced with downstream distance (Smith, 1972), since water temperatures are inversely related to flow volumes and the buffering effects of flow volumes on water temperatures become more pronounced with downstream distance. A consequence of this dynamism is that water temperature varies along the longitudinal

* To whom all correspondence should be addressed.

II: +27332605490; fax:+27332605818;

e-mail: 912419341@ukzn.ac.za

Received 28 April 2004; accepted in revised form 14 July 2004. axis of a river, on a seasonal and daily basis (Webb and Walling, 1985; Allan, 1995), with diurnal fluctuations superimposed on seasonal and annual cycles (Webb and Walling, 1985).

In spite of many thermal characteristics of rivers being regarded as universal, South Africa's rivers have their own distinct characteristics. Ward (1985), in comparing the thermal characteristics of Northern Hemisphere vs. Southern Hemisphere rivers, concluded that what makes Southern Hemisphere rivers distinct from Northern Hemisphere rivers is "a matter of degree rather than of kind”, i.e. South African rivers may have parallels in the Northern Hemisphere, but a greater proportion of these will be more variable than in the Northern Hemisphere. Chiew et al. (1995) have demonstrated that Southern African rivers, like Australian rivers, have extreme flow regimes, displaying twice the world average of flow variability. There is currently renewed interest, particularly in the Northern Hemisphere, in understanding the thermal regime of rivers and streams, due to anticipated alterations to the natural thermal regimes of many rivers (Johnson, 2003). This may be a consequence of impoundments, changes in land use, and climate change (Mohseni et al., 1999), which lead to changes in flow regimes. Altered flow regimes typically lead to a reduction in the range of temperature variation, even though mean temperatures may remain unchanged (Gray and Edington, 1969; Smith 1972; Wootton, 1992). Changing the thermal regime of a river significantly alters a component of the environment for which river organisms are adapted (tolerances and life cycle cues) (Appleton, 1976; Ward, 1985). Water temperature variability has been positively correlated with species diversity (Vannote et al., 1980). The importance of variability in maintaining ecosystem health and integrity is now well recognized (Richter et al., 1997); when variability is lost, there may be a consequent impoverishment of biological communities (Smith, 1972).

A limited understanding exists of the temperature conditions of natural rivers (Smith 1979; Johnson, 2003), especially in the Southern Hemisphere (Ward, 1985). This is certainly true of the rivers of the Sabie catchment, to a lesser degree for the intra-annual water temperature dynamics (Jewitt et al., 1998), and to a greater degree for the inter-annual cycles. The Sabie River is of particular 


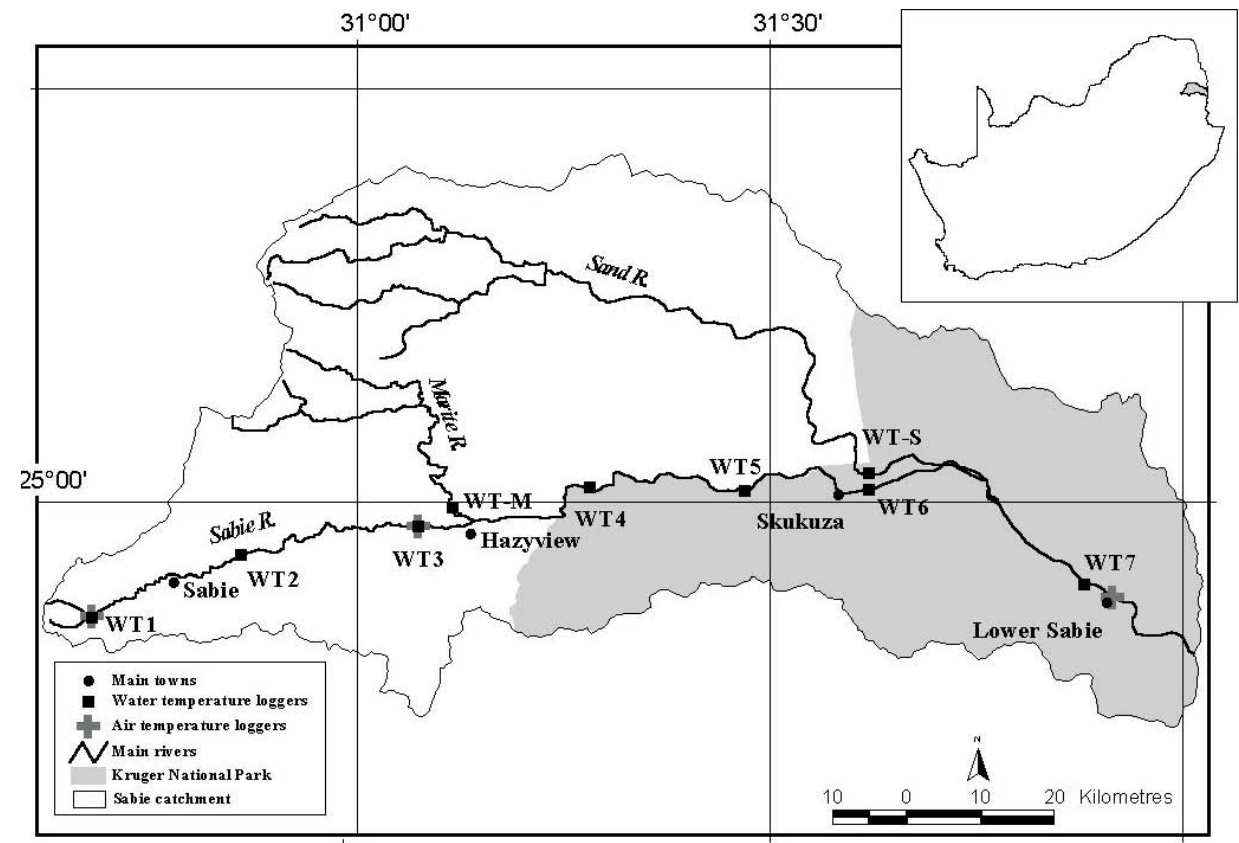

Figure 1

Water temperature monitoring sites within the Sabie catchment. The portion of the Kruger National Park falling within in the Sabie catchment is shown (shaded) together with main towns.

TABLE1

Site information for nine water temperature monitoring sites within the Sabie catchment. Downstream distance is calculated from the source of the Sabie River; consequently this parameter does not apply to the sites on either the Sand or the Marite River sites (N/A).

\begin{tabular}{|l|c|c|c|c|c|c|c|}
\hline Site & River & $\begin{array}{c}\text { Logger } \\
\text { depth } \\
\mathbf{( m )}\end{array}$ & $\begin{array}{c}\text { Channel } \\
\text { width } \\
\mathbf{( m )}\end{array}$ & $\begin{array}{c}\text { Altitude } \\
\mathbf{( m} \\
\text { a.m.s.I.) }\end{array}$ & $\begin{array}{c}\text { Latitude } \\
\text { (decimal } \\
\left.{ }^{\circ} \mathbf{S}\right)\end{array}$ & $\begin{array}{c}\text { Longitude } \\
\text { (decimal } \\
\left.{ }^{\circ} \mathrm{E}\right)\end{array}$ & $\begin{array}{c}\text { Down- } \\
\text { stream } \\
\text { distance } \\
\mathbf{( k m )}\end{array}$ \\
\hline WT1 & Sabie & 0.35 & 4.80 & 1193 & 25.14 & 30.68 & 5.87 \\
WT2 & Sabie & 0.50 & 13.00 & 870 & 25.06 & 30.86 & 30.09 \\
WT3 & Sabie & 0.60 & 13.30 & 523 & 25.04 & 31.07 & 57.29 \\
WT4 & Sabie & 3.00 & 25.00 & 357 & 24.98 & 31.31 & 83.85 \\
WT5 & Sabie & 0.50 & 5.00 & 287 & 24.99 & 31.47 & 106.94 \\
WT6 & Sabie & 0.50 & 28.00 & 242 & 24.99 & 31.62 & 125.17 \\
WT7 & Sabie & 1.00 & 6.00 & 157 & 25.10 & 31.89 & 160.90 \\
WT-S & Sand & 0.30 & 3.00 & 237 & 24.97 & 31.63 & N/A \\
WT-M & Marite & 0.35 & 20.00 & 443 & 25.02 & 31.13 & N/A \\
\hline
\end{tabular}

catchment, from 1 June 2001 and 31 May 2003. Seven of the water temperature sites were situated along the longitudinal axis of the Sabie River (Fig. 1), which is the main river of the Sabie catchment, in order to provide data on intra-annual changes in water temperature along the longitudinal axis of the Sabie River. Additional sites on the Marite and Sand Rivers, which are the main tributaries of the Sabie River, allowed for comparisons of water temperatures between the major rivers of the Sabie catchment. Pertinent site information is provided in Table 1.

Water temperatures were recorded using Hobo (H8 series) single-channel data loggers (Onset, 1999) containing internal temperature sensors (thermisters). Such equipment has been used successfully elsewhere for recording water temperatures (see for example Lewis, 1999; Robison et al., 1999). The Hobo loggers were sealed within waterproof polycarbon submersible cases mounted inside steel pipes, which were immersed in flowing water at a depth of at least $0.35 \mathrm{~m}$, and attached to anchor points (rocks or trees) using $3 \mathrm{~mm}$ steel cable. Sites were chosen based on proximity to anchor points, stability of channel bottom, and cryptic value (i.e.

interest to environmental hydrologists in South Africa since it exhibits a "cold-finger" effect (a cold river in a warm terrestrial system), with fish species typical of the upper cold water reaches also occurring, anomalously, in the warmer lowveld region (Weeks et al., 1996). This paper highlights general trends in intra-annual water temperature variability in the Sabie River, at the catchment scale, based on hourly water temperatures collected in the Sabie catchment over the period 1 June 2001 to 31 May 2003. A basic understanding of these characteristics is central to understanding the links between water temperatures and aquatic fauna, and for designing appropriate river management strategies.

\section{Methods}

Hourly water temperatures were collected at 9 sites, ranging from $1190 \mathrm{~m}$ a.m.s.l. (top site) to $157 \mathrm{~m}$ a.m.s.l. (lowest site), together with hourly air temperatures at three sites, within the Sabie reduced risk of theft or damage). The thermisters were calibrated using water baths of $0^{\circ} \mathrm{C}$ and $50^{\circ} \mathrm{C}$, and found to be accurate to approximately $0.5^{\circ} \mathrm{C}$. Water temperature data were downloaded every 2 to 3 months. Three temperature/relative humidity Hobo loggers (Hobo H8 pro-Series Temp/RH) (Onset, 1999) located at sites within one kilometre of the Sabie River, and mounted inside radiation shields (Davis, 2000) attached to steel poles at a height of $1 \mathrm{~m}$ from the ground, were used to record hourly air temperatures.

A subset of loggers was chosen to summarise catchment trends. Sites WT1 and WT7 were selected based on their location at the upper and lower extremes of the catchment respectively, while site WT3 was selected as a "middle" site. The time lag between hourly air and water temperatures was estimated using simple linear regression, and taking the highest correlation $\left(\mathrm{R}^{2}\right)$ between water temperatures and air temperatures lagged from 0 to $4 \mathrm{~h}$. Hourly proportion curves, showing the percentage time hourly water temperatures fell within $1^{\circ} \mathrm{C}$ class intervals over the two year study 
Figure 2

Hourly water (WT) and air (AT) temperatures from 1 to 30 June 2001 for sites on the upper (WT1) and lower (WT7)

Sabie River. Air temperatures correspond to the lower Sabie River site.

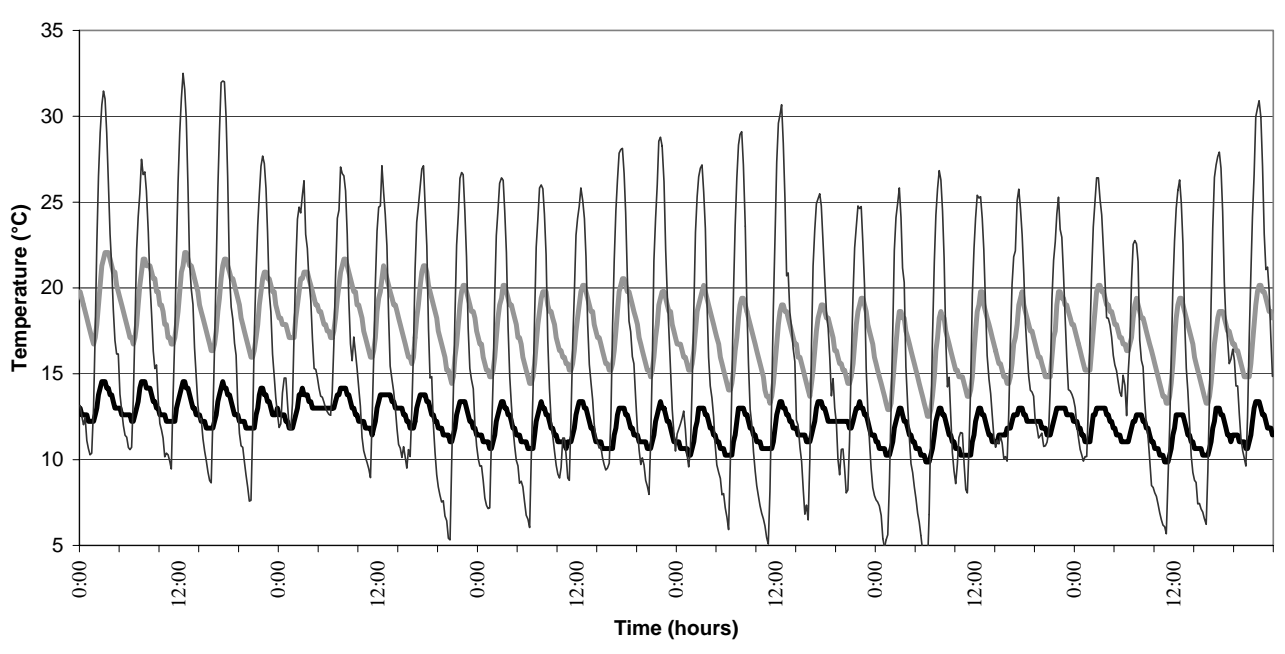

Figure 3

Hourly water (WT) and air (AT) temperatures from 1 to 31 December 2001 for sites on the upper (WT1) and lower (WT7) Sabie River. Air temperatures correspond to the lower Sabie River site.

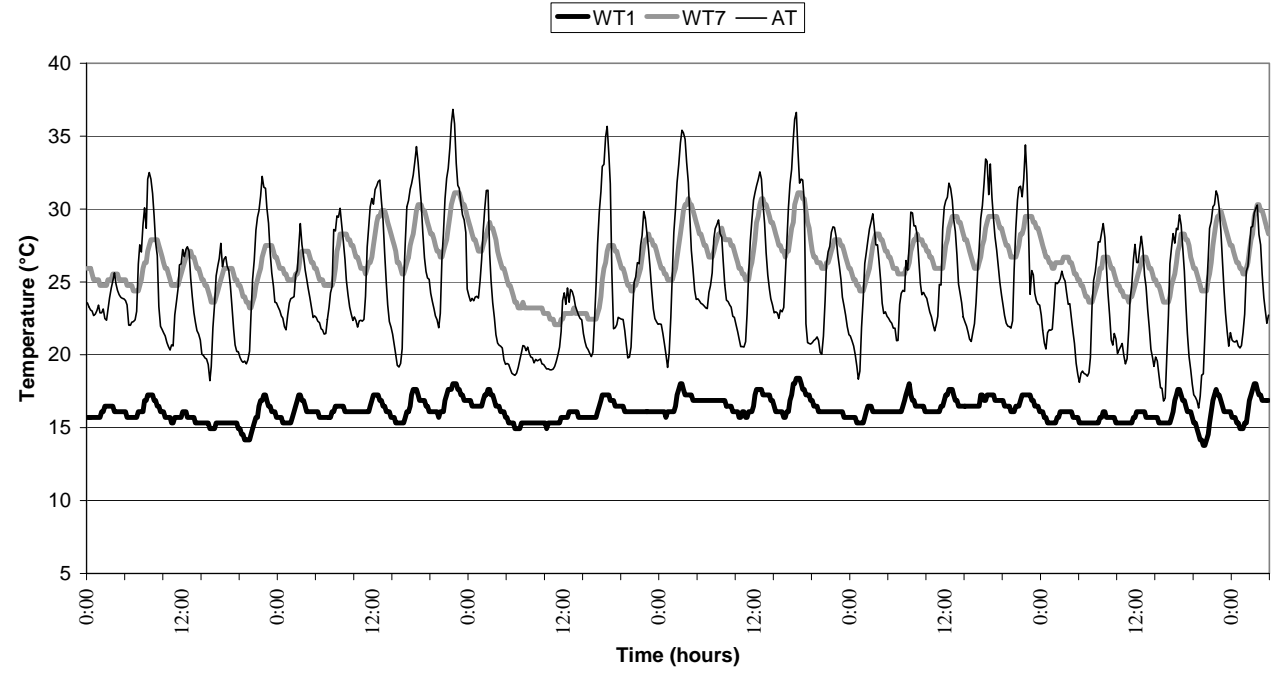

period, were calculated for sites at the upper (WT1), "middle" (WT3) and lower (WT7) reaches of the Sabie River. These curves were derived by ranking hourly water temperatures from lowest to highest, performing a frequency count of water temperatures within each class interval, and finally converting these to percentage values. Mean daily ranges for each site were obtained by calculating the annual average of the daily range (maximum to minimum) of water temperatures. Hourly water temperatures for each logger were analysed in order to provide data on daily means, minimums and maximums of water temperatures. Box-and-Whisker plots of water temperature as a function of downstream distance were used to illustrate water temperature changes with downstream distance (which is used in this document as a generic term, inherent within which are the effects of flow volume, altitude and geomorphology). Daily duration and cumulative degree-day curves for temperatures greater than $15^{\circ} \mathrm{C}$ were used to provide information on the sequence in which the Sabie River was heated on an annual basis. This threshold was chosen as it corresponded with the median water temperature at the upper catchment site (WT1) (cf. Fig. 5).

\section{Results: Thermal variation at the catchment scale}

Hourly air and water temperature data plotted for June and December 2001 for the upper and lower catchment sites on the Sabie River
(Figs. 2 to 3) are typical of trends for the entire record length, with daily range and variability of water temperatures increasing along the longitudinal axis of the Sabie River. The data also showed clear diurnal trends, which were more pronounced in June than in December. The time lag between air and water temperatures was shown to increase from 1 to $3 \mathrm{~h}$ with downstream distance (Table 2). In other words, the diurnal pattern of water temperatures followed that of air temperatures, but with a $1 \mathrm{~h}$ time lag upstream and increasing to $3 \mathrm{~h}$ with downstream distance.

\section{TABLE2}

$\mathbf{R}^{2}$ values for simple linear regression of air vs. water temperature at 0 to $4 \mathrm{~h}$ time lags of water temperatures. $R^{2}$ values of highest significance are shaded.

\begin{tabular}{|l|c|c|c|c|c|}
\hline \multirow{2}{*}{$\begin{array}{l}\text { River } \\
\text { position }\end{array}$} & \multicolumn{5}{|c|}{ Time lag (hours) and $\mathbf{R}^{2}$ value } \\
\cline { 2 - 6 } & $\mathbf{0}$ & $\mathbf{1}$ & $\mathbf{2}$ & $\mathbf{3}$ & $\mathbf{4}$ \\
\hline Upper Sabie & 0.657 & 0.705 & 0.701 & 0.649 & N/A \\
\hline Middle Sabie & 0.542 & 0.604 & 0.635 & 0.630 & 0.594 \\
\hline Lower Sabie & 0.467 & 0.510 & 0.534 & 0.538 & 0.521 \\
\hline
\end{tabular}




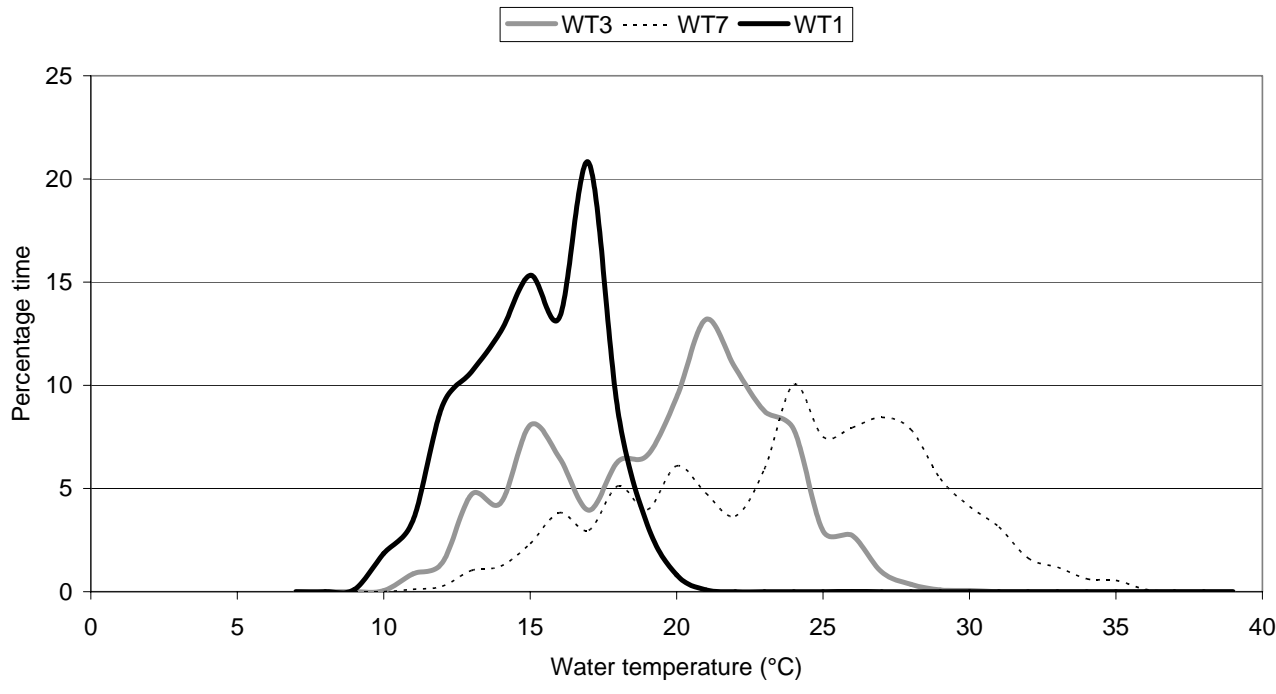

Figure 4

Hourly proportion curves

for sites on the upper,

middle and lower reaches

of the Sabie River, based

on hourly water

temperatures from 1 June

2001 to 31 May 2003.

\section{Figure 5}

Box-and-whisker plot of daily water temperatures from 1 June 2001 to 31 May 2003 as a function of downstream distance. Maximum and minimum water temperatures are shown as "whiskers", while the middle $50 \%$ of the data for each site is shown by each box. The median is shown as a line within the box.

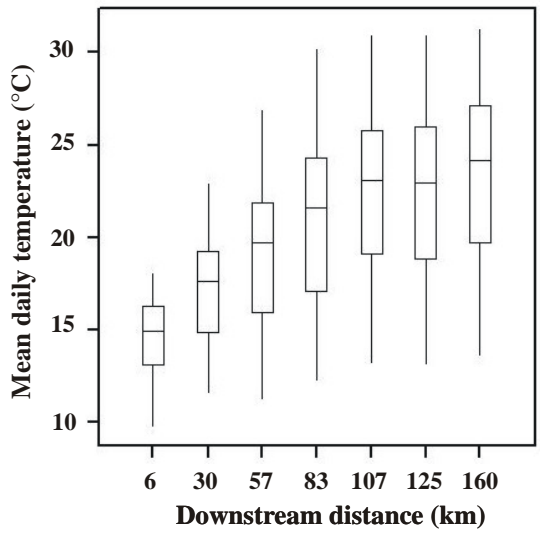

$\square \operatorname{Max} \square \operatorname{Min}$

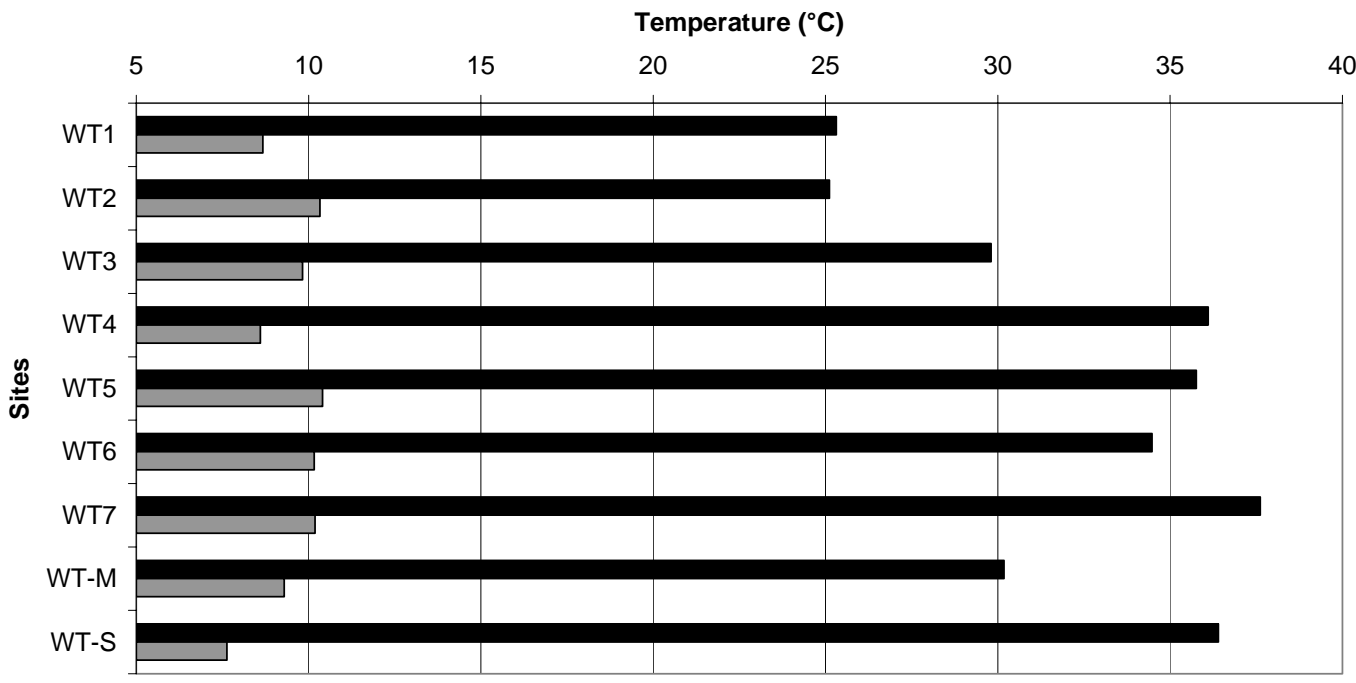

Figure 6 Absolute daily minima and maxima of water temperatures from the nine water temperature sites within the Sabie catchment from 1 June 2001 to 31 May 2003
Based on the data for the sites for the upper, middle and lower sections of the Sabie River, the intra-annual thermal regime became more complex with downstream distance. This was further substantiated in the plot of water temperature versus percentage time within different temperature classes (Fig. 4). These curves changed from unimodal (WT1) to multimodal (WT7) along the longitudinal axis of the Sabie River. Water temperatures became progressively warmer for longer periods with downstream distance.

When hourly water temperatures were summarised to provide mean daily water temperature statistics, catchment scale patterns became more evident. A box-and-whisker plot of 7 water temperature sites for the period 1 June 2001 to 31 May 2002 (Fig. 5) showed that median water temperatures increased with downstream distance, as did the range of the middle $50 \%$ of the data. Minimum values remained relatively constant, while mean maximum water temperatures increased with downstream distance.

Absolute daily minima and maxima did not show a clear downstream trend (Fig. 6). Observed water temperatures within the 
Figure 7

Average annual daily

range in water

temperatures between 1

June 2001 and 31 May

2003 as a function of

downstream distance on

the Sabie River. Daily

ranges increased between

57 and 83 kilometres

downstream of the

headwaters.

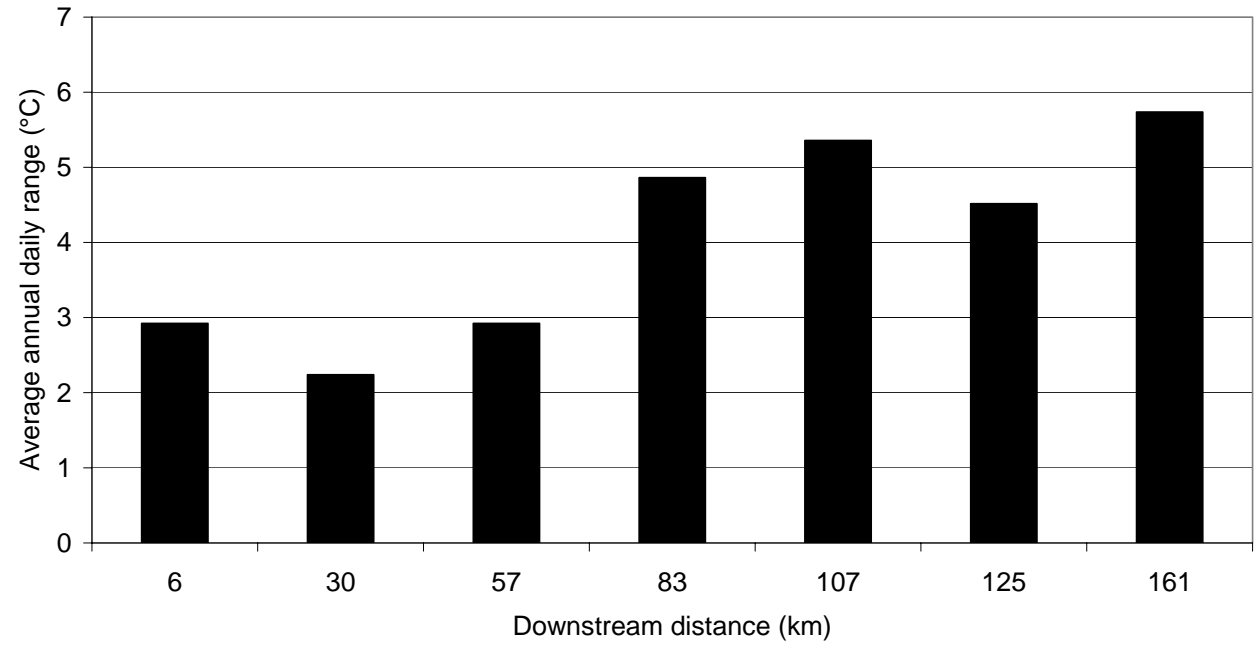

Figure 8

Cumulative degree days greater than $15^{\circ} \mathrm{C}$ for the upper, middle and lower reaches of the Sabie River. The time scale is provided as Julian days, while the site suffixes (-1 and -2) correspond to the periods 1 June 2001-31 May 2002, and 1 June 2002-31 May 2003 respectively.

Figure 9

Duration curves of water temperature for the upper, middle and lower reaches of the Sabie River based on mean daily water temperatures from 1 June 2001 to 31 May 2003.

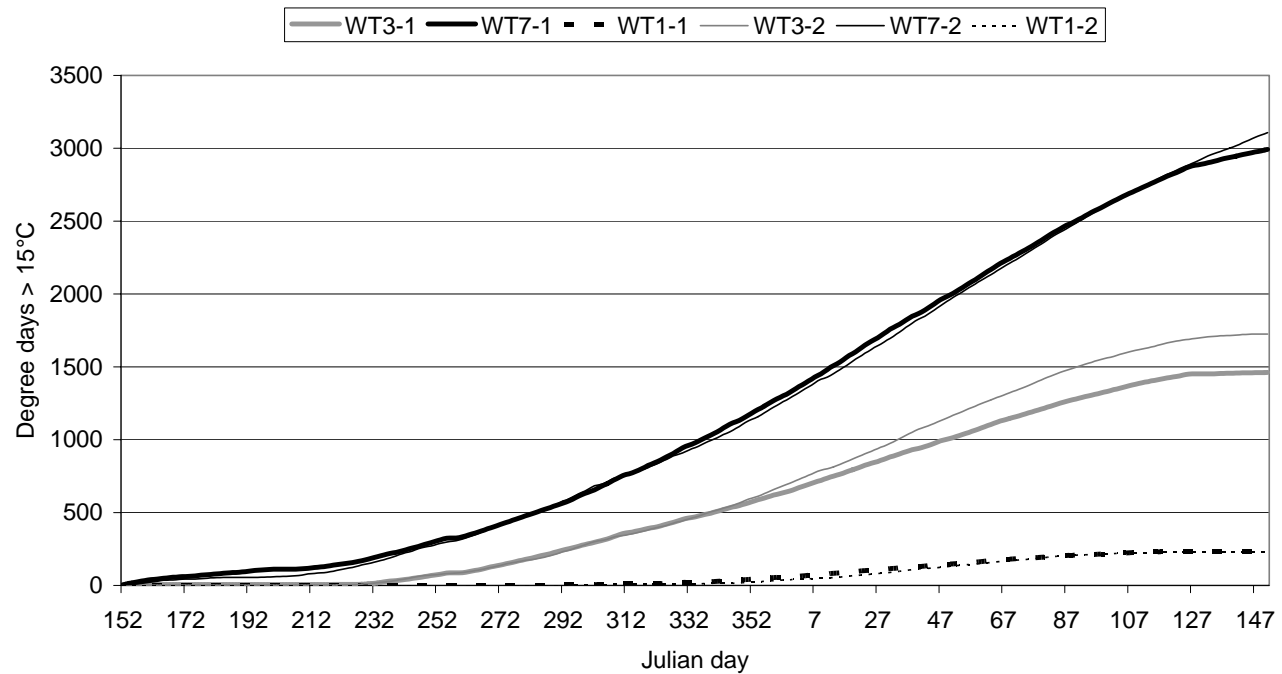

-WT3 -WT7 -WT1

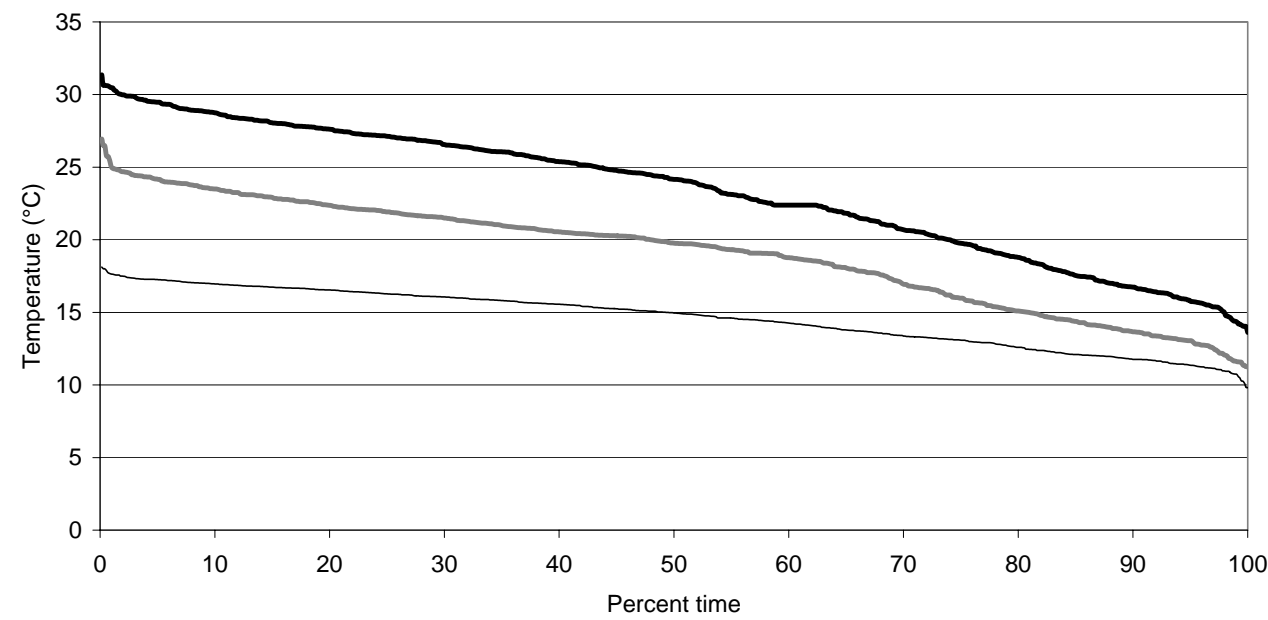

Marite (WT-M) and Sand (WT-S) Rivers displayed higher maxima and lower minima than those recorded from adjacent sites in the Sabie River - WT3 and WT6, respectively, although these differences were more marked for the Sand River than the Marite River. The average annual daily water temperature range (Fig. 7) could be divided into two groups, viz. the sites from 0 to $57 \mathrm{~km}$ downstream, and sites from 57 to $160 \mathrm{~km}$ downstream, with sites downstream of $57 \mathrm{~km}$ showing a greater daily range.
The upper, middle and lower sections of the Sabie River showed different patterns of water heating sequences, as represented by cumulative degree day and duration curves (Figs. 8 to 9). Thermal energy was progressively added with downstream distance, as shown by the increase in cumulative degree days greater than $15^{\circ} \mathrm{C}$. This heating sequence was consistent for both years of water temperature data analysed, with cumulative degree day curves following similar trends at each site(Fig. 8). The difference in heating 


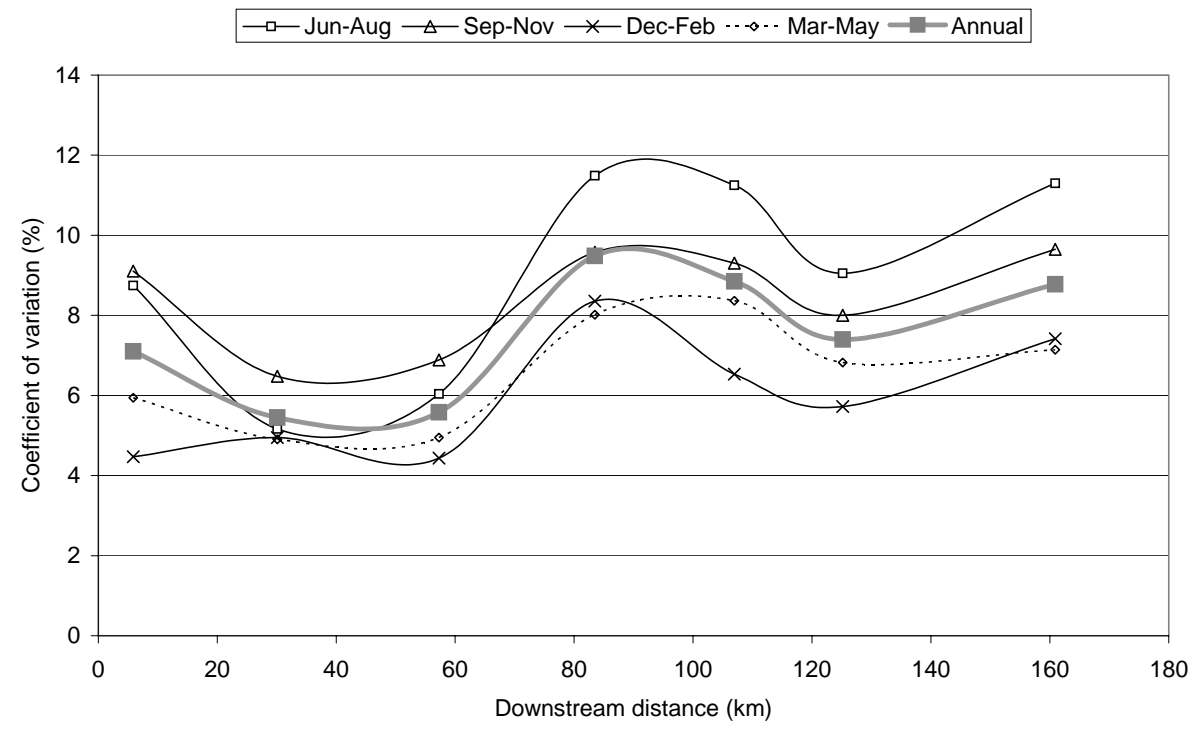

Figure 10

Annual seasonal coefficient of variation (\%) of mean daily water temperatures in the Sabie River as a function of downstream distance, based on mean daily water temperatures for the period 1 June 2001 to 31 May 2003.

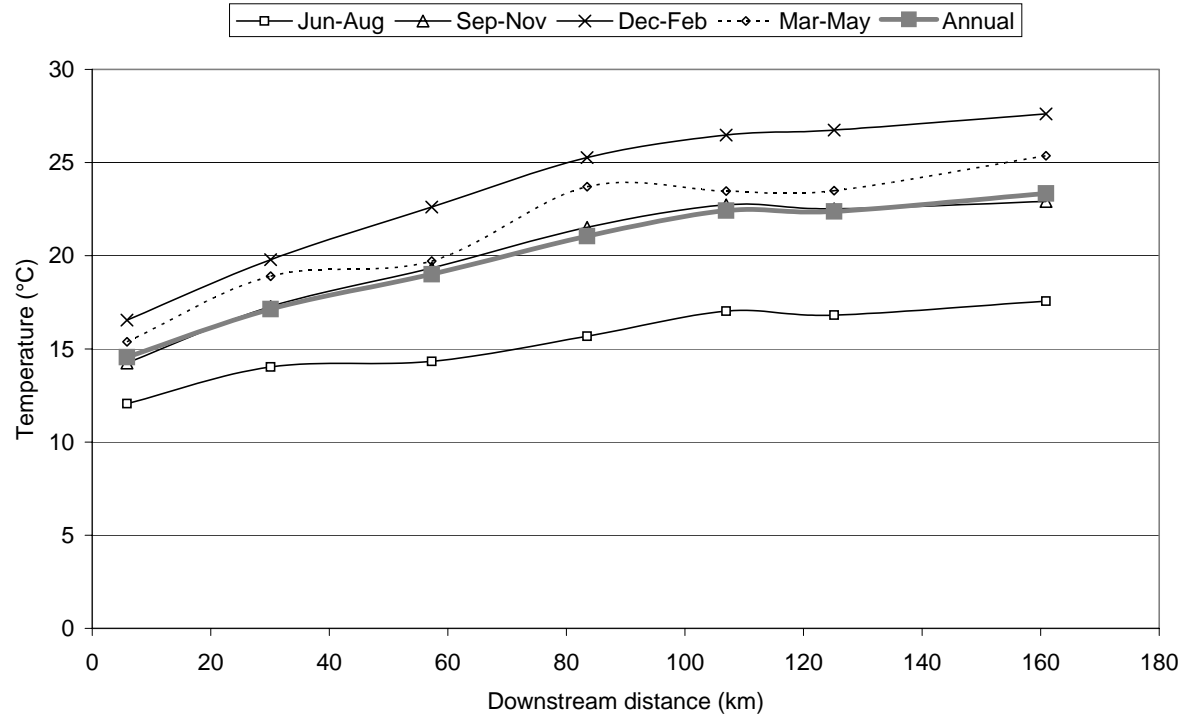

Figure 11

Mean daily seasonal and annual water temperatures along the longitudinal axis of the Sabie River for the period 1 June 2001 to 31 May 2003

sequence between WT3-1 and WT3-2 could not be explained based on the data available. The percentage time spent at different temperatures (Fig. 9) varied for each section of the Sabie River examined. Based on these duration curves, a warming of 4 to $14^{\circ} \mathrm{C}$ occurred between upper and lower sites.

In general, variability increased with downstream distance, as shown by the percentage coefficient of variation (an expression of the sample standard deviation expressed as a percentage of the sample mean), which was calculated from mean daily water temperatures expressed as a seasonal mean with an associated standard deviation (Fig. 10). However, sites between 20 and 57 km downstream from the headwaters showed a decrease in variability. The underlying reasons for this may be due to a combination of factors such as groundwater inputs, residency times of water and more stable air temperatures at higher altitudes. There was a marked difference in variability between the seasons, with the greatest variability being recorded for the winter months (June to August). This same seasonal pattern was also evident in the mean annual water temperatures along the longitudinal axis of the Sabie River (Fig. 11). The warmest temperatures were in summer (December to February), while the coolest water temperatures were during winter (June to August). In general, water temperature increased progressively downstream.

\section{Discussion}

Essig (1998) defines three water temperatures of concern to environmental hydrologists, viz:

- True water temperature (i.e. actual water temperature at a given time within the cross-section of interest);

- The water temperature near the temperature sensor. Sensors are often near banks, where the water tends to be more sluggish, and thus warmer

- Recorded water temperatures, which are a function of the accuracy and calibration of the logger

Thus, the quality of the data is a function of the accuracy of the temperature loggers themselves, as well as in the choice of appropriate locations within the river channel. The choice of location is critical in ensuring that recorded water temperatures are representative of the reach of the river being considered. Loggers should be placed in well-mixed areas, such as riffles, and not in contact with the river bottom, to avoid issues of cold or warm pockets, and thermal stratification (Lewis et al., 2000). However, these considerations need to be balanced against threats from vandalism and animal damage, as was the case in this study. The data from this 
study will at best approximate true water temperatures occurring on the river bed, due to the $0.5^{\circ} \mathrm{C}$ resolution of the Hobo loggers. The difference between true water temperatures and the water temperatures near the loggers is not quantifiable, although it is accepted that such differences might be found owing to the location of the loggers. Anon. (1998) found that a logging interval of one hour was adequate for measuring biologically meaningful water temperatures, and numerous ecological studies (for example Anon., 1998; Sullivan et al., 2000; Caissie et al., 2001) have used the same logging interval. For this study, the derivation of seasonal trends was considered more important than a high level of accuracy at an hourly time step, owing to the scale of the research.

The proportion, duration and degree day curves highlight broad catchment-scale thermal trends. In general, mean and maximum temperatures, as well as thermal variability, increased with downstream distance in the Sabie River. This trend is consistent with those proposed by Vannote et al. (1980) as part of the river continuum concept. These trends are likely to be the result of complex interactions between, inter alia, river geomorphology, flow volume (and how this varies seasonally), lateral inputs from tributaries, altitude, and solar radiation (Poole and Berman 2001). For example, lateral flow inputs from tributaries (Marite and Sand Rivers) may affect water temperatures in the Sabie River by adding warmer water at the point of confluence, and contributing to thermal variability, due to the observed higher maxima and lower minima within these two tributaries ( $c f$. Fig. 6). A combination of such factors may explain the apparent anomaly of the coefficient of variation being highest during the winter months, since this coincides with the low flow period, such that the buffering effects of flow volumes on water temperatures are reduced, and water temperatures are consequently more sensitive to air temperatures. An additional factor that may explain this phenomenon is that during the winter months, cloud cover is generally less, such that the diurnal radiation flux (and air temperature) has a wider diurnal range than experienced during the summer months, as was evident from the hourly plots. Within each reach, a sinusoidal pattern with a $24 \mathrm{~h}$ periodicity was visible for both air and water temperatures, although the oscillations of the water temperatures were dampened.

An additional variable not considered in this study was the role of hyporheic flow in buffering water temperatures. For example, Fowler and Scarsbrook (2002) found that the water temperature in areas of down-welling was equal to the temperature in the stream channel, while the water temperature in areas of up-welling was cooler, due to river water mixing with cooler groundwater. Thus, water temperatures cannot be fully understood without due consideration of a river's hyporheic zone. Within the middle and lower portions of the Sabie River, the role of this buffer was considered negligible, due to the large degree of bedrock control within the macro-channel (Heritage et al., 1997). In the middle and lower reaches, the Sabie River is confined to a narrow deep valley within existing host rock, and active channel evolution and sedimentation are restricted to within this “macro-channel” zone (Van Niekerk and Heritage, 1993). However, the role of hyporheic flow may nevertheless play a limited role within the macro-channel, which does display some alluvial characteristics (Heritage et al., 1997). Such flows may also play a more significant role in the upper reaches of the Sabie River, together with the more alluvial Sand River. It is well known that the rocky upper reaches of the Sabie River are dominated by dolomitic substrata, which is known to provide groundwater inflow to rivers. These variable inputs of ground and surface water have important ecological implications, not only in terms of nutrient supply and water temperatures, but also in terms of the hypogean invertebrate communities (Fowler and Scarsbrook, 2002) and fish survival (Malcolm et al., 2003). The extent of influence of the hyporheic zone within different reaches of the Sabie-Sand River systems could be quantified using piezometer nests (i.e. a cluster of bank-side boreholes at different depths) positioned at areas of down-welling and up-welling, such as the head and tail of riffles (Gordon et al., 1994; Fowler and Scarsbrook, 2002; Malcolm et al., 2003). Additionally, residence times of hyporheic flows could be determined using hydrochemical tracing techniques (Malcolm et al., 2003).

Based on the data from this study, the Sabie River can be divided into two distinct thermal zones. These zones coincide with the zones suggested by Weeks et al. (1996), who grouped the fish species assemblage of the Sabie River into two groups; a cool water group (foothill zone) and a warm water group (lowveld zone). Within the Sabie River system, it was suggested by Weeks et al. (1996) that the ichthylogical patterns observed were largely explained by thermal patterns. Further scope for research on the ecological significance of water temperatures in this river system exists in studying the seasonal dynamics and magnitude of the "coldfinger" effect mentioned in the introduction. This could be achieved by simulating water temperatures using an appropriate water temperature model, and comparing the residuals between observed and simulated water temperatures within the transition region of the lowveld and foothill zone, near Hazyview. Consistent oversimulations of water temperatures during the year within this region could provide an objective method of quantifying the "cold-finger" effect, which is reflected in the fish community patterns, together with elucidating the seasonal nature of this effect.

\section{Conclusions}

It is important to understand the drivers of, and patterns in, water temperatures at different spatial and temporal scales, particularly within catchment systems of ecological importance, such as the Sabie River. Such research enables the establishment of reference thermal conditions within river systems, as well as characterizing a river's thermal "signature". This approach provides the basis for detecting changes in the thermal regime of a river, as well as adding to the understanding of inter-annual variability and how this changes with longitudinal distance. Further research should aim to deepen the understanding of the relative importance of different thermal drivers and buffers, particularly the roles of tributaries and the hyporheic zone, within variable river systems such as the Sabie. Such research provides the basis for understanding the impacts of climate change, and activities which may result in flow reductions, on water temperatures, as well as links between cumulative seasonal water temperatures and aquatic community patterns.

\section{Acknowledgements}

We gratefully acknowledge the Water Research Commission and the University of Natal Research Fund for funding. Thanks are also due to the Kruger National Park's Scientific Services for field assistance, Rhodes University's Institute for Water Research for logistical support, as well as the following people, for accommodating the Hobo loggers on their properties: Roy Charsley; Barrie and Michelle Pretorius; and Alex and Natalie Durr.

\section{References}

ALLAN JD (1995) Stream Ecology: Structure and Function of Running Waters. Chapman \& Hall, London.

ANONYMOUS (1998) FSP Technical Notes: Stream Temperature Sampling Frequencies Explored. Forest Science Project. <www.humboldt.edu/ fsp/techreports.apr98technote.pdf $>$. 
APPLETON CC (1976) Observations on the thermal regime of a stream in the Eastern Transvaal, with reference to certain aquatic Pulmonata. S. Afr. J. Sci. 72 20-23.

BARTHOLOW JM (1989) Stream temperature investigations: field and analytic methods. Biol. Reports 89(17). <www.krisweb.com/ biblio/general/usfws/bartholo.pdf $>$

CAISSIE D, EL-JABI N and SATISH MG (2001) Modelling of maximum daily water temperatures in a small stream using air temperatures. J.Hydrol. 251 14-28.

CHIEW, FHS, MCMAHON, TA and PEEL, MC (1995) Some issues of relevance to South African streamflow hydrology. Proc. $7^{\text {th }} S$. Afr. Hydrol. Symp..Grahamstown, South Africa, Rhodes University.

DAVIS (2000) Davis Instruments. <http://www.davisnet.com>.

DUNHAM J, SCHROETER R and RIEMAN B (2003) Influence of maximum water temperature on occurrence of Lahontan Cutthroat trout within streams. N. Am. J. Fish. Manage. 2310421049.

ESSIG DA (1998) The dilemma of applying uniform temperature criteria in a diverse environment: an issue analysis. Idaho Division of Environmental Water Quality, Boise, Idaho. <www.krisweb.com/ biblio/general/misc/essigidahotemp.pdf $>$.

FOWLER RT and SCARSBROOK MR (2002) Influence of hydrologic exchange patterns on water chemistry and hyporheic invertebrate communities in three gravel-bed rivers. N. Z. J. Mar. Freshwater Res. 36 471-482.

GORDON ND, MCMAHON TA and FINLAYSON BL (1994) Stream Hydrology: An Introduction for Ecologists. John Wiley and Sons, Chichester.

GRAY JRA and EDINGTON JM (1969) Effect of woodland clearance on stream temperature. J. Fish. Res. Board Can.. 26(2)399-403.

HERITAGE GL, VAN NIEKERK AW, MOON BP, BROADHURST LJ, ROGERS KH and JAMES CS (1997) The Geomorphological Response to Changing Flow Regimes of the Sabie and Letaba River Systems. WRC Report No. 376/1/97. Water Research Commission, Pretoria.

JEWITT GPW, WEEKS DC, HERITAGE GL and GÖRGENS AHM (1998) Modelling Abiotic-Biotic Links in the Rivers of the Kruger National Park, Mpumalanga, South Africa. WRC Report No. 777/ 1/98. Water Research Commission, Pretoria.

JOHNSON SL (2003) Stream temperature: scaling of observations and issues for modelling. Hydrol. Proc. 17 497-499.

LEWIS T (1999) Stream Temperature Protocol. Humboldt State University - Forest Science Project, Arcata, CA. <http:// www.krisweb.com/stream/temp.htm>.

LEWIS TE, LAMPHEAR DR, MCCANNE DR, WEBB AS, KRIETER JP and CONROY WD (2000) Regional Assessment of Stream Temperatures Across Northern California and their Relationship to Various Landscape-Level and Site-Specific Attributes. Forest Science Project. Humboldt State University Foundation., Arcata, CA. <www.humboldt.edu/ fsp/>.

MALCOLM IA, SOULSBY C, YOUNGSON AF and PETRY J (2003) Heterogeneity in ground water-surface water interactions in the hyporheic zone of a salmonid spawning stream. Hydrol. Proc. 17 601-617.

MOHSENI O, ERICKSON TR and STEFAN HG (1999) Sensitivity of stream temperatures in the United States to air temperatures projected under a global warming scenario. Water Resour. Res. 35(12) 3723-3733.

NIKOLSKY GV (1963) The Ecology of Fishes. Academic Press, London.

ONSET (1999) Hobo Data Loggers. Onset Computer Corporation, 470 MacArthur Blvd., Bourne, MA 02532.

POOLE GC and BERMAN CH (2001) Pathways of human influence on water temperature dynamics in stream channels. Environ. Manage. 27(6)787-802.

RICHTER BD, BAUMGARTNER JV, WIGINGTON, R and BRAUN DP (1997) How much water does a river need? Freshwater Biol. 37 231-249.

ROBISON EG, RUNYON J and ANDRUS C (1999) Cooperative Stream Temperature Monitoring: Project Completion Report for 1994-1995 Oregon Department of Forestry. <www.odf.state.or.us/ FP/MonitoringBMPs/Projects>.

SMITH K (1972) River water temperatures - an environmental review. Scottish Geog. Mag. 88 211-220.

SMITH K (1979) Temperature characteristics of British rivers and the effects of thermal pollution. In: GE Hollis, (ed.) Man's Impact on the Hydrological Cycle in the United Kingdom. Geo Abstracts Ltd., Norwich. pp229-242.

SMITH K (1981) The prediction of river water temperatures. Hydrol. Sci. Bull. 26 19-32.

SULLIVAN K, MARTIN DJ, CARDWELL RD, TOLL JE and DUKE S (2000) An Analysis of the Effects of Temperature on Salmonids of the Pacific Northwest with Implications for Selecting Temperature Criteria. Sustainable Ecosystems Institute, Portland, Oregon. $\leq$ www.sei.org/downloads/reports/salmon2000.pdf $>$.

VAN NIEKERK AW and HERITAGE GL (1993) Geomorphology of the Sabie River: An Overview and Classification. Report No. 2/93. Centre for Water in the Environment, University of the Witwatersrand, Johannesburg.

VANNOTE RL, MINSHALL GW, CUMMINS KW, SEDELL JR and CUSHING CE (1980) The river continuum concept. Can. J. Fish.Aquat. Sci. 37 130-137.

VANNOTE RL and SWEENEY BW (1980) Geographic analysis of thermal equilibria: A conceptual model for evaluating the effect of natural and modified thermal regimes on aquatic insect communities. Am. Nat. 115(5)667-695.

WARD JV (1982) Ecological aspects of stream regulation: responses in downstream lotic reaches. Water Pollut. Manage. Rev. (New Delhi) 2 1-26.

WARD JV (1985) Thermal characteristics of running waters. Hydrobiol. 125 31-46.

WEBB BW. and NOBILIS F (1997) Long-term perspective on the nature of the air-water temperature relationship: A case study. Hydrol. Proc. 11137-147.

WEBB BW and WALLING DE (1985) Temporal variation of river water temperatures in a Devon river system. Hydrol. Sci. 30(4) 449-464

WEEKS DC, O'KEEFFE JH, FOURIE A and DAVIES BR (1996) A Pre-Impoundment Study of the Sabie-Sand River System, Mpumalanga, with Special Reference to Predicted Impacts on the Kruger National Park. Vol. I: The Ecological Status of the SabieSand River System. WRC report no. 294/1/96. Water Research Commission, Pretoria.

WOOTTON RJ (1992) Fish Ecology. Blackie, Glasgow. 